\title{
Identidades corporales de las mujeres rumanas en España: del totalitarismo a la falsa libertad
}

\author{
Body determined Identities \\ of Romanian Women in Spain: \\ From Totalitarianism to False Freedom
}

\author{
Catalina Iliescu \\ Universitat d'Alacant
}

\section{RESUMEN}

Este estudio se propone observar la presentación social del cuerpo en el caso de la mujer rumana durante los últimos decenios de la dictadura comunista y los cambios surgidos tras su relocalización en un mundo cambiante (la década postcomunista), así como las modificaciones que la experiencia migratoria opera en la reconstrucción de su identidad. A pesar de reivindicar en teoría la igualdad entre sexos, la doctrina de la Rumanía totalitaria la contradecía de facto en la práctica diaria. Mientras en apariencia, la retórica igualitaria suprimía los valores androcéntricos, estos eran en realidad reforzados por el Estado paternalista-opresivo. El cuidado del cuerpo no merecía atención en una sociedad cuyo discurso imponía una mujer carente de identidad femenina y cuya imagen pública pasaba a un segundo plano en el momento de formar un hogar y procrear. Tras la caída de la dictadura, el cuerpo de la mujer se percibe cada vez más como una estrategia para la movilidad social.

Palabras clave: Cuerpo, Migración, Identidad de género, Norma social.

\section{SUMMARY}

After the fall of the dictatorship, the female body began to be regarded as a strategy for social mobility. Starting from their own accounts, this study seeks to observe how Romanian women socially presented their bodies over the last years of communist dictatorship and the modifications which came about as women adapted to a changing world (i.e. the post-communist decade), as well as the impact that the experience of migration had on the reconstruction of their identities. Despite claiming in theory to promote sexual equality, the totalitarian doctrine of the Socialist Republic of Romania contradicted it in daily practice. While allegedly suppressing androcentric values, these were actually reinforced by a paternalistic-oppressive state. Looking after one's appearance did not merit attention in a society forging a discourse in which the prevailing type of 
woman lacked a feminine identity and whose public image was pushed into the background as soon as she got married and had children.

Key words: Body, Migration, Gender Identity, Social Norm.

\section{OBJETIVOS Y METODOLOGÍA}

En este trabajo pretendo ofrecer una descripción y análisis de la identidad corporal desde una perspectiva de género, centrada en la realidad de las mujeres rumanas residentes en España, prestando atención a los cambios y continuidades sobrevenidos en el cuerpo femenino rumano en contextos de control político totalitario y en situación migratoria a un país democrático como es España. Para ello me serviré, además de mi propia experiencia como rumana también afincada en España, de las entrevistas realizadas a un pequeño grupo escogido que considero que posee representatividad por sus características de edad, clase social y estudios. Tomaré en consideración la última década de la dictadura comunista (años 1980) en Rumanía a través de las narraciones de las mujeres entrevistadas para compararla con la transición postcomunista (años 1990), observando las condiciones de relocalización dentro de un marco cambiante. Asimismo, analizaré después las modificaciones que la experiencia migratoria pudo haber acarreado.

Tras un breve repaso del marco teórico en el que este estudio se sitúa, proporcionado por la antropología del cuerpo y una de sus líneas de trabajo más recientes, centrada en la presentación social del cuerpo, trataré conceptos empleados en este estudio, tales como son "apariencia", "modificación corporal", "control político de la corporeidad", así como el contexto y premisas de mi análisis.

La parte empírica de este trabajo se centra en el análisis de las entrevistas guiadas llevadas a cabo en los años 2009-2010 con ocho mujeres rumanas residentes en España (Alicante y Coslada), quienes ofrecen narraciones de sí mismas relacionadas con el poder y la dictadura, con los ideales estéticos anteriores y actuales, con la construcción y reconstrucción de su identidad en situación diaspórica y el papel que en todo ello juega su cuerpo (imagen corporal). El estudio se centra en la corporeidad de mujeres migrantes por dos razones: en primer lugar, por ser las mujeres las principales depositarias de tradiciones ligadas al cuerpo; en segundo lugar, por ser el género una variable relevante en los estudios antropológicos del cuerpo, y una categoría central, además de transversal, susceptible o no, según comprobaremos, de sufrir alteraciones o verse afectada por la situación 
migratoria. El estudio se realiza a partir de voces femeninas, aunque no en oposición con la masculinidad, ya que está presente en el discurso de estas mujeres protagonistas de las políticas represivas de antes de 1989 y del nuevo orden postcomunista que otorga al cuerpo un lugar central, aunque diferenciador, potenciador de desigualdades.

Para no caer en la tentación de uniformizar culturas, tal como advierte Esteban que suele ocurrir al hablar del cuerpo (2004: 27), hemos intentado tener en cuenta datos diferenciadores como el colectivo de procedencia, el nivel de experiencia, así como los cambios históricos (en nuestro caso, antes y después de 1989) y la variabilidad interna del grupo social, ya que algunas decisiones sobre la imagen corporal tienen que ver con la profesión, religión, edad o entorno. Nuestras ocho informantes forman un grupo diverso en cuanto a edad, formación y rango social (véase la tabla adjunta); en la mayoría de los casos, la actividad desempeñada en España es de categoría inferior a su preparación o experiencia profesional en Rumanía. Todas ellas proceden del medio urbano en Rumanía, aunque algunas pasaron su infancia y adolescencia en el medio rural. Por razones de privacidad, todas ellas reciben en este trabajo un nombre ficticio. El método por el que optamos fue el cualitativo basado en la entrevista guiada, durante la cual estas ocho mujeres relatan una historia de segundo grado, pues su narración es una interpretación o construcción personal de la realidad. En las entrevistas aparecen muchos elementos que identifican y hacen única cada experiencia, pero también hay motivos que se repiten, mostrando aquello que estas mujeres comparten (el estereotipo étnico, el recuerdo de la censura, cierto desacuerdo con la imagen femenina actual en los medios de comunicación). Realizadas individualmente, grabadas y transcritas íntegramente, cada entrevista abarca 88 preguntas desarrolladas sobre tres ejes cronológicos (totalitarismo, transición, experiencia migratoria) y estructuradas en torno a los siguientes bloques temáticos derivados del concepto de apariencia: indumentaria, peinado y adornos en diversos contextos (trabajo, consulta médica, ocio, celebraciones, visitas al país de origen); cuidados del cuerpo (higiene, cosmética, pilosidades); y modificaciones corporales (tatuajes, piercings, cirugía). Otra categoría abordada en el guión de la entrevista fue la de cambios de estilo con respecto al periodo previo y posterior a la migración, así como preguntas que pretendían indagar en aspectos como: la muerte y el luto, el mito de la maternidad, los ideales de belleza, o la herencia religiosa. 


\begin{tabular}{|c|c|c|c|c|}
\hline & ANA & BIANCA & FLORICA & GINA \\
\hline Edad & 49 & 42 & 31 & 35 \\
\hline $\begin{array}{l}\mathrm{N}^{2} \text { habitantes } \\
\text { localidad procedencia }\end{array}$ & $68.450^{1}$ & 227.981 & 69.049 & 1.944 .451 \\
\hline $\begin{array}{l}\text { Tiempo en España } \\
\text { (años) }\end{array}$ & 9 & 3 & 7 & 8 \\
\hline Rol en familia & $\begin{array}{l}\text { Esposa } \\
\text { Madre }\end{array}$ & $\begin{array}{c}\text { Divorciada con } \\
\text { pareja } \\
\text { Madre }\end{array}$ & $\begin{array}{l}\text { Divorciada con } \\
\text { pareja } \\
\text { Futura Madre }\end{array}$ & $\begin{array}{l}\text { Esposa, } \\
\text { Madre }\end{array}$ \\
\hline Ocupación en origen & Enseñanza & $\begin{array}{l}\text { Obrera, Industria } \\
\text { Textil }\end{array}$ & $\begin{array}{c}\text { Pintora, } \\
\text { Diseñadora, } \\
\text { Restauradora }\end{array}$ & Traductora \\
\hline $\begin{array}{l}\text { Ocupación en destino } \\
\text { y situación laboral }\end{array}$ & Empleada Hogar & Empleada Hogar & $\begin{array}{l}\text { Operadora } \\
\text { Tráfico empresa } \\
\text { Transportes }\end{array}$ & $\begin{array}{l}\text { Traductora } \\
\text { autónoma, } \\
\text { Enseñanza }\end{array}$ \\
\hline Nivel educativo & $\begin{array}{c}\text { Bachiller }+ \\
\text { Escuela Arte }\end{array}$ & $\begin{array}{l}\text { Obligatoria (10 } \\
\text { cursos) }\end{array}$ & Universitaria & Universitaria \\
\hline Religión & Ortodoxa & Ortodoxa & Ortodoxa & $\begin{array}{l}\text { Ortodoxa (no } \\
\text { practicante) }\end{array}$ \\
\hline $\begin{array}{l}\text { Nivel económico en } \\
\text { origen }\end{array}$ & Medio & Medio-bajo & Medio-bajo & Medio-alto \\
\hline $\begin{array}{l}\text { Nivel económico en } \\
\text { destino }\end{array}$ & Medio & Medio & Medio & Medio \\
\hline Medio (rural/urbano) & $\begin{array}{c}\text { Infancia: Rural, } \\
\text { Desde } \\
\text { adolescencia: } \\
\text { Urbano }\end{array}$ & Urbano & $\begin{array}{c}\text { Infancia: Rural, } \\
\text { Desde } \\
\text { adolescencia: } \\
\text { pequeña ciudad } \\
\text { provincias }\end{array}$ & Urbano \\
\hline
\end{tabular}

\begin{tabular}{|c|c|c|c|c|}
\hline & ELENA & IOANA & CORINA & DANA \\
\hline Edad & 29 & 54 & 52 & 31 \\
\hline $\begin{array}{l}\text { № habitantes } \\
\text { Localidad procedencia }\end{array}$ & 70.060 & 204.880 & 70.060 & 70.060 \\
\hline $\begin{array}{l}\text { Tiempo en España } \\
\text { (años) }\end{array}$ & 6 & 8 & 10 & 5 \\
\hline Rol en familia & $\begin{array}{c}\text { Soltera sin } \\
\text { pareja, } \\
\text { Hija }\end{array}$ & $\begin{array}{l}\text { Esposa, } \\
\text { Madre }\end{array}$ & $\begin{array}{l}\text { Esposa, } \\
\text { Madre }\end{array}$ & $\begin{array}{c}\text { Soltera con } \\
\text { pareja } \\
\text { Hija }\end{array}$ \\
\hline Ocupación en origen & Estudios Instituto & Maestra & Administrativa & $\begin{array}{c}\text { Estudios } \\
\text { Universitarios }\end{array}$ \\
\hline $\begin{array}{l}\text { Ocupación en destino y } \\
\text { situación laboral }\end{array}$ & $\begin{array}{l}\text { Médico en } \\
\text { prácticas }\end{array}$ & Educadora & Empleada Hogar & $\begin{array}{c}\text { Mediadora } \\
\text { Intercultural }\end{array}$ \\
\hline Nivel educativo & Universitaria & $\begin{array}{c}\text { Bachiller }+ \\
\text { Especialidad }\end{array}$ & Bachillerato & Universitaria \\
\hline Religión & Neoprotestante & $\begin{array}{c}\text { Ortodoxa } \\
\text { (no practicante) }\end{array}$ & Neoprotestante & Neoprotestante \\
\hline $\begin{array}{l}\text { Nivel económico en } \\
\text { origen }\end{array}$ & Medio-bajo & Medio-alto & Medio-bajo & Medio-bajo \\
\hline $\begin{array}{l}\text { Nivel económico en } \\
\text { destino }\end{array}$ & Medio & Medio & Medio & Medio \\
\hline Medio (rural/urbano) & $\begin{array}{c}\text { Urbano: } \\
\text { Pequeña ciudad } \\
\text { de provincias }\end{array}$ & $\begin{array}{c}\text { Infancia: rural, } \\
\text { Desde } \\
\text { adolescencia: } \\
\text { urbano }\end{array}$ & $\begin{array}{c}\text { Infancia: rural, } \\
\text { Desde } \\
\text { adolescencia: } \\
\text { urbano }\end{array}$ & Urbano \\
\hline
\end{tabular}

${ }^{1}$ Populaţia României pe localităţi la 1 ianuarie 2010, ISSN: 2066-2181. (Bucarest: Institutul Naţional de Statistică). 


\section{MARCO TEÓRICO}

A lo largo de su historia, el ser humano ha establecido diversas relaciones con su cuerpo que nunca han sido unívocas. El cuerpo ha servido de herramienta y ha provocado expectativas; ha sido realidad física pero percibida a través de los mecanismos de construcción simbólica, puesto que, tal y como señala Le Breton (1990: 27), sólo cobra sentido con la mirada cultural de la persona. El cuerpo depende de las narrativas que un modelo social determinado produce.

Lo que le debemos a la antropología del cuerpo es la revelación de que el ser humano construye social y culturalmente su cuerpo, cuya dimensión biológica no se enfrenta, sino que se incluye en su dimensión cultural. Martí observa que, con los siglos, nuestra idea sobre el cuerpo ha cambiado (nos martirizamos en los gimnasios, nos sometemos a dietas draconianas, nos obstinamos en broncearnos la piel), es decir que modificamos nuestro cuerpo por un ideal de belleza y atractivo personal, por marcar un momento o una etapa importante en nuestra vida, o porque queremos expresar nuestra individualidad, o nuestra pertenencia a un grupo (Martí 2008: 10).

La teoría social del cuerpo es un enfoque relativamente reciente, aunque el interés por la corporeidad se remonta varios siglos atrás. Hoy en día el cuerpo es "nudo de estructura y acción" y "centro de reflexión antropológica" desde múltiples perspectivas, bien tradicionales (física, cultural, filosófica), bien modernas (feminista, de la salud, del arte) (Esteban 2004: 19). Desde que Marcel Mauss descubrió que convertirse en individuo social implica un aprendizaje corporal, ha habido muchas y variadas contribuciones a este campo. Foucault a su vez, analiza los cambios sociales desde las políticas sobre el cuerpo, explicando cómo la corporeidad se procesa en diferentes contextos y cómo los sujetos resisten desde sus propios cuerpos. Por su parte, Bourdieu rompe con la tradición separadora corporeidad-actor, ocupándose del gusto, el habitus y la relación entre cuerpo y clases sociales.

Es innegable que el cuerpo ha adquirido últimamente una importancia creciente, manifestada en las medidas de higiene, la industria del fitness, productos dietéticos, body art, defensa de la desnudez o de la plenitud sexual, todas ellas características de la sociedad actual, cuya elasticidad en la opcionalidad contrasta con la rigidez de la codificación en la presentación del cuerpo en las sociedades tradicionales. En el caso de nuestro estudio veremos que las mujeres sufren dos impactos: el encuentro con la sociedad española con una estética más libre, relajada y colorida, y el reencuentro con la sociedad rumana, con una nueva estética basada en la 
supremacía o incluso la "tiranía de la belleza" (Menéndez 2006: 69) como una nueva fórmula de control.

Dentro del triángulo básico (el yo, el cuerpo y la sociedad) las personas damos señales de nuestra interacción al codificar — según criterios de rol, estatus y situacionalidad- nuestra presentación del cuerpo, de modo que éste se convierte en un texto interpretable. Su valor simbólico se materializa en acciones — gestos y técnicas corporales- y en imagen, la cual viene condicionada por tres ámbitos (Martí 2008: 18): (1) el cuidado general del cuerpo (higiene, estética, pilosidades); (2) la indumentaria (con el doble fin de cubrir y también de celebrar las formas corporales); (3) las modificaciones corporales (que revelan información sobre personalidad o pertenencia y exclusión).

La presentación social del cuerpo (en la que confluyen lo biológico y lo cultural), además de tener la capacidad de conducir a cambios sociales, expresa un posicionamiento personal, social y político. La representación y construcción de la identidad, tanto personal como social, son indivisibles. La identidad es lo que nos define dentro del colectivo y nos delimita frente a otros, por lo que la apariencia es fundamental en la identificación con un grupo o con una manera de pensar. En las entrevistas veremos que algunas de las mujeres rumanas empleadas en hogares españoles no quieren destacar, ni llamar la atención, y, por eso, se visten modestamente, a diferencia de como visten en su vida privada.

La presentación corporal emana poder o subordinación. A través de sus instrumentos (los cuidados del cuerpo, la indumentaria o las modificaciones corporales) se expresan las posibles prestaciones del individuo en una relación social, se dan indicios para clasificar socialmente o se comunica qué tipos de intercambios son los que la persona desea mantener. En uno de los testimonios que veremos, Florica narra que en su puesto de atención al público en una academia, su vestimenta clásica, sobria, traída de su país, comunicaba una determinada manera de pensar acerca de la enseñanza y los valores que engloba, hasta que su jefe le indicó la conveniencia de lucir un estilo escotado y ajustado, que ella adoptó como exigencia del puesto de trabajo. En este caso, un instrumento corporal como es la indumentaria, transmite un mensaje falso, que no pertenece al yo, sino que viene impuesto externamente, lo cual constituye un ejemplo de subordinación emanada de la presentación corporal.

Dentro de la sociología del cuerpo, uno de los campos que han retenido la atención científica, ha sido el de las técnicas de mantenimiento de la corporeidad, donde se incluyen las conductas de higiene que muestran una gran heterogeneidad en función de la sociedad, cultura o clase que se considere, y los cuidados, tanto privados (baño), como públicos (peluquería, 
manicura). En la sociedad rumana decimonónica rural, la mujer era la responsable de las tareas relacionadas con la higiene, señala Bărbulescu (2005: 323), tanto la corporal de los miembros de la familia, como la del hogar y de la vestimenta, costumbre que ha perdurado hasta hoy en día. En el caso que nos ocupa, algunas de las mujeres rumanas entrevistadas, señalan cambios en sus conductas debido a la experiencia migratoria, bajo influencia de hábitos de la sociedad receptora y más exactamente del grupo donde ha tenido lugar el proceso de aculturación.

Para Le Breton «el cuerpo aparece como objeto concreto de investidura colectiva, como soporte de las escenificaciones y de las semiotizaciones, como motivo de distanciamiento o de distinción..." (2002: 81). En el testimonio de una de nuestras entrevistadas (Ioana) se entrevé este distanciamiento o distinción que el cuerpo marca. En Rumanía pertenecía a un determinado grupo social, con unas posibilidades económicas y una respetabilidad e independencia que se ven mermadas en España. En su narración se denota una visión jerárquica que se visibiliza precisamente a través de la corporeidad: "las que eran inferiores a mí lo siguen siendo" refiriéndose a la vestimenta y accesorios, aunque sus enunciados desvelan el hecho de que la migración no ha incrementado su bienestar. Habla con cierta nostalgia del estándar del que gozaba en Rumanía: "no es que en España me haya emancipado, pero, quizás la única diferencia está en los accesorios, ya que perfumes también tenía antes, incluso más finos, porque estaba mejor de dinero; podía comprarme lo que quería, mientras que ahora lo que tengo es una hipoteca. Nunca tuve hipoteca en Rumanía".

Una idea que atraviesa los siglos es la de la maternalización del cuerpo femenino. Empezando por Esquilo (Euménides), advierte Chasseguet-Smirgel (2003: 93), se entrevé la idea de que la madre es una portadora, una especie de horno en el que el panadero (padre) introdujo el pan, una nodriza del germen concebido. La lucha feminista contra el destino biológico de la mujer trata de liberarla de su papel pasivo en la sociedad. La prohibición de los métodos anticonceptivos y el aborto han transformado en diversas épocas y partes del mundo, el vientre fecundo en una maldición; en el caso rumano dan testimonio de ello los médicos quienes tenían, durante la aplicación del denominado Decreto $770^{2}$, un plan anual de natalidad, cuyas cifras, impuestas por el Estado (y el partido único), se debían cumplir bajo penalización con el 15\% del salario mensual o pena de varios años de cárcel en caso de interrupción del embarazo (Kligman 2000: 81).

En su visión del cuerpo como nudo de acción, experiencia y economía política, Esteban reconoce el auge que han tomado las actividades corpo-

\footnotetext{
${ }^{2}$ Decreto promulgado en 1966 en el que se prohibía el aborto y la contracepción.
} 
rales en la sociedad occidental actual, transformando el cuerpo en un mediador cultural y últimamente, en un "objeto en sí mismo"; algo a mostrar, a reivindicar (Esteban 2004: 67). Pérez Gauli (2000: 10) lo define como un punto de reflexión introspectiva y un medio de representación del modelo de belleza y Soley-Beltrán (2005: 430) lo ve como signo de identidad personal. Una nueva tendencia narcisista dentro de la corriente esteticista y consumista, hace que el cuerpo se transforme en un símbolo de estatus, juventud, salud, energía, incluso de movilidad social, tal y como ocurre en la sociedad rumana durante la transición postcomunista.

Un fenómeno novedoso, característico de la sociedad actual, es el equilibrio entre la inducción al consumo y al mismo tiempo su represión, ambos polos ejerciendo control sobre lo corporal desde la alimentación, el ejercicio físico, los cuidados estéticos y la sexualidad, a fin de llenar el vacío existencial del yo basado en trabajo, producción y consumo. En este sentido, Esteban (2004: 70) dota el "juicio social" de la capacidad de condicionar nuestro comportamiento, no sólo a través de la autocensura, o sentimiento de culpabilidad, sino en las normas que gobiernan el crecimiento (peso), la conservación (higiene), la presentación (cosmética, vestimenta) y la expresión afectiva del cuerpo.

En el nuevo milenio, los modelos culturales rinden culto de manera exacerbada a lo corporal (el cuerpo deviene la máxima representación, la máxima conciencia de la identidad humana) y venden un patrón de bienestar social, una promesa de eterno éxito a través de un cuerpo femenino delgado y sexy, de canon seductor y de un cuerpo masculino atlético y musculado, de canon vigoroso. Vemos pues cómo el ideal corporal deja de ser únicamente femenino, y tanto los hombres como las mujeres empiezan a gestionar su imagen para negociar su lugar en la sociedad (asistimos últimamente a una sexualización del cuerpo masculino en los medios de comunicación, hecho remarcado también por nuestras entrevistadas, por ejemplo Gina). La diferencia entre los dos modelos corporales es que el masculino ofrece una visión holística, por presentar un cuerpo-instrumento, mientras el femenino adopta una perspectiva fragmentada, parcelada; un cuerpo-expresión. Pérez Gauli (2000: 175) habla de la "corporeidad cárnica" en una narración fraccionada de la anatomía femenina que caracteriza lo visual en las culturas occidentales de las décadas de 1980 y 1990, donde es frecuente ver espaldas, glúteos, piernas, troncos de mujeres sin cabeza.

La identidad corporal, tanto en el proceso de socialización a lo largo de la vida, como en las vivencias individuales o grupales del cuerpo, así como en el tratamiento y utilización social del cuerpo y su imagen en todos los niveles y grupos sociales, sigue perpetuando, advierte Esteban (2004: 77) una diferenciación hombre-mujer. 


\section{CONTEXTO Y PREMISAS DE ESTE ESTUDIO}

El presente estudio se centra en el periodo anterior a la caída del régimen comunista en Rumanía (diciembre de 1989), especialmente el octavo decenio del siglo, recordado como profundamente sombrío en términos económicos, sociales, de terror y opresión, de pérdida de esperanza y libertades más elementales, en comparación con la década de los años 90, caracterizada por la transición al sistema capitalista con cambios mayores en todos los aspectos de la vida, y finalmente complementado por el primer decenio del nuevo milenio que coincide, en nuestro estudio de caso, con una experiencia diaspórica en la vida de las mujeres rumanas entrevistadas, pues representa la época de su traslado a España y el inicio de su proceso de aculturación. Trataremos pues el contexto rumano antes y después de la caída de la dictadura, para referirnos luego al fenómeno migratorio rumano con destino a España, siempre desde una perspectiva centrada en las mujeres, puesto que son sus discursos los que proporcionan el corpus para la parte analítica de este trabajo.

\section{El totalitarismo}

En la época post-bélica, a partir de 1947 con la instauración del gobierno comunista, una mujer, Ana Pauker es nombrada titular de la cartera más importante del gobierno: exteriores. Se quería desde el Kremlin dar la imagen de una transformación de la posición y condición de la mujer. En realidad fue ésta una época de ideologización y afiliación forzada al partido comunista de las mujeres, al tiempo que se destruían las instituciones feministas, según señala Târău (2002: 137).

La emancipación femenina que recorre Europa tras la segunda guerra y que permite la doble afirmación de la mujer en el hogar y en la sociedad se reduce en Rumanía a una farsa, ya que las mujeres sufren la doble opresión de la dependencia económica y doméstica. Morar-Vulcu (2002: 199) detecta en las modalidades polares de identificación propias del marxismoleninismo (clase obrera versus burguesía; intelectuales progresistas versus reaccionarios) la ausencia de un par dicotómico para la categoría "mujer", por lo que en el discurso comunista, la mujer aparece definida en simetría con otros grupos como el campesinado, los obreros, con una etiqueta tipo, donde se incluían los roles que podía desempeñar (obrera, ingeniera, maestra, educadora) y las competencias (cocina, conservas caseras, cultivo de hortalizas, hogar). Lo que llama la atención según Morar-Vulcu (2002: 204) 
es la presencia masiva de afirmaciones de tipo "la mujer ha de ser convencida, aleccionada, activizada, se le tiene que explicar", que conllevan la presunción implícita de pasividad o inferioridad intelectual. La otra definición está basada en diferenciaciones por subcategorías (miembro de partido, esposa de miembro, campesina colectivizada, campesina obrera).

En su análisis de la Revista Femeia ("La Mujer"), órgano de difusión de la ideología reinante, pero al mismo tiempo el único material con cierta trayectoria ${ }^{3}$ dirigido a las mujeres, Bodeanu observa cómo la revista se hace eco de cada nueva etapa o normativa en las políticas estatales (2002: 146). Con la entrada en vigor del decreto 770 (1 de octubre 1966) contra el aborto, la revista empieza una larga serie de campañas de concienciación de las parejas sobre su deber y responsabilidad de asegurar la juventud y el vigor de la nación. A medida que la realidad del sistema comunista va degradándose, se pasa del ideal femenino de los años 60 (mujer trabajadora, casada y con dos o tres hijos) al de la "madre heroína" en los 70 (mujer casada, con mucha descendencia), mientras que en los 80 lo único que se predica es el número de hijos (preferiblemente 5-6 por familia) y se observa a la vez un puritanismo excesivo que elimina del discurso público cualquier referencia al sexo (censura que se hace extensiva a la literatura y al cine hasta el extremo de eliminar los besos) según recuerdan varias de nuestras entrevistadas. La madre soltera oprobiada en los 60, es tolerada en los 70 y ejemplarizada en los 80, aunque la realidad de los orfanatos muestra un crecimiento preocupante del número de hijos no deseados, fruto de una política demográfica draconiana.

El libro de Kligman (2000) nos proporciona un estudio amplio y pormenorizado sobre la política natalista en Rumanía, mientras que Cormoş (2006) ofrece una radiografía del sistema represivo y punitivo que castigaba a las mujeres, a los médicos, a personas intermediarias y familiares que tuvieran cualquier tipo de implicación en una interrupción de embarazo. Kligman (2000: 53) muestra que la normativización de la reproducción afectaba a la mujer, a la familia, a la relación entre sexos y entre generaciones, así como a las actitudes ante la reproducción. Otros países, como España, ya experimentaban una construcción de género desigual y castigadora del cuerpo (Roca 1996: 13) a través de estructuras como la división del trabajo, el poder y la autoridad o el control del contexto emocional, relacional y sexual, ejercido por la Iglesia que en la posguerra acaparó el ámbito ideológico, institucional y de poder político, así como el de la educación

\footnotetext{
${ }^{3}$ Otras muestras de prensa femenina de inspiración soviética son estudiadas por Cosma (2002).
} 
(ibid: 22). Tal política es llevada a cabo en Rumanía (a diferencia de España, donde el discurso religioso, axiomático es el que regula y normativiza la totalidad de la experiencia vital humana, focalizándola en la dicotomía pecado-virtud) por el Estado paternalista que, bajo el pretexto de proteger a la familia, determina los ciclos reproductivos de la población prohibiendo los abortos y los métodos anticonceptivos e introduciéndose de este modo en el territorio privado del cuerpo. El ideal procreador en la España franquista, marcada por el fascismo europeo, tiene detrás del principio moral eclesiástico (Roca 1996: 243) documentado en textos papales que consideran la contracepción igual de pecaminosa que el adulterio, un trasfondo demográfico ("número es potencia") que obedece al ideal expansionista de nación superpoblada que le devolvería a España su vocación de imperio tras la baja natalidad de la época anterior (debida a la guerra, pero también a la emancipación de la mujer y su acceso al mercado laboral y a la educación) señala Roca (ibid: 233). En la mayor parte del siglo XX los métodos anticonceptivos no fueron permitidos en Rumanía ni en el medio urbano ni en el rural. La población recurría al aborto en último caso si fallaban los demás métodos (coitus interruptus, ciclo menstrual, lavados o remedios con plantas). En este sentido, Roca (ibid: 249) cita como las únicas dos prácticas anticonceptivas en la España de Franco, el coito interrumpido y la continencia periódica (método Ogino-Knauss, conocido como «ruleta-vaticana" por su azarosa fiabilidad y cierta condescendencia por parte de la Iglesia) mientras que para abortar, las mujeres españolas acudían a médicos, comadronas, curanderos o remedios caseros en función de su poder económico.

Con el decreto 770 comienza la época más negra para las mujeres rumanas, pues regula como únicos casos posibles de interrupción del embarazo: 1) peligro sobre la vida de la madre; 2) enfermedad grave hereditaria de uno de los progenitores; 3) la invalidez física/psíquica de la embarazada; 4) la edad de más de 45 años (que más tarde sube a 49 años); 5) tener más de 4 (luego 5) hijos paridos y a su cargo; 6) embarazo como fruto de un incesto o violación. Estos casos se estudiaban por una comisión en la que estaban representadas varias instituciones, y la mujer era la que debía aportar pruebas (certificadas) que avalaran su situación en alguno de estos supuestos (Kligman 2000: 67). En caso de que la mujer tuviera que ser intervenida urgentemente porque su vida corría peligro, el médico debía llamar al fiscal y al forense, quienes determinaban la necesidad del aborto. Si había indicios de que no era espontáneo, se abría una investigación judicial. La inclusión del aborto en el código penal (con penas de cárcel de hasta tres años) marca el comienzo de una etapa represiva, cruel e inhumana sobre la población, especialmente la femenina. El jefe de la sec- 
ción de obstetricia de cada hospital se convierte en un guardián. El instrumental médico se guarda bajo custodia y hay que seguir un protocolo kafkiano para poder acceder a él ${ }^{4}$.

La humillación y el miedo públicos, el dolor y la ira privados, las dificultades diarias (físicas, emocionales, económicas), los riesgos que asumía la mujer (y muchas veces sus seres cercanos), la falta de intimidad en sus vidas cotidianas, hicieron del espacio vital de las mujeres un infierno de miedo, humillación, dolor y desesperación. Debido al control estatal sobre su fertilidad, muchas vieron su cuerpo como un arma íntima usada por el régimen para infiltrar el miedo (Kligman 2000: 199), y su sexualidad acompañada por la angustia, llevaba finalmente al deterioro de la pareja. La amenaza de un embarazo enajenaba a la mujer frente a su propio cuerpo, cuyos órganos reproductivos eran una especie de enemigo interno. Según muestra Massino (2004) la reducción de la natalidad aparece como un elemento de resistencia ante las políticas invasoras del Estado, la opresión física y el terror psicológico.

\section{El POST-COMUNiSMO}

Tras la caída de la dictadura en 1989 y el comienzo del periodo de transición al modelo capitalista, es inevitable que permanezca latente una herencia totalitarista relevante sobre todo en el caso de las mujeres maduras que detentan una posición social adquirida en el sistema anterior (Pasti 2003: 99), al mismo tiempo que las relaciones entre hombres y mujeres ya consolidadas durante la dictadura, son las que sirven como punto de partida en la transición. Según Pasti (2003: 101), las políticas de género en el comunismo supusieron mejoras rápidas y múltiples en el modelo tradicional, atenuando las diferencias existentes entre sexos en la sociedad precapitalista interbélica, pero sus efectos fueron negativos, debido a la pésima calidad de vida durante el comunismo y a la aplicación de estas políticas a la fuerza, lo cual produjo su rechazo.

Las políticas del totalitarismo seguían reproduciendo el dominio del hombre, sustituyendo el patriarcado privado por uno público. Así, por ejem-

${ }^{4}$ En España, la Jefatura del Estado dicta en 1941 la ley Sobre el aborto y la protección de la natalidad, y en 1944 la del aborto (donde se incluye tanto la expulsión prematura voluntariamente provocada del producto de la concepción, como su destrucción en el vientre de la madre) se tipifica como delito en el Código Penal (Libro II, Título VIII, Capítulo III) con penas recogidas en 15 artículos (Roca, ibid: 249) que oscilan entre 2 y 6 años de prisión para el responsable, llegando hasta 11 si éste tiene estudios sanitarios. 
plo, en el cuidado de los hijos, la baja maternal era sólo para la madre, mientras que la ayuda económica por hijos la recibía el padre. Estudios sobre la dotación del hogar, muestran que hoy en día siguen primando los aparatos de uso común: televisión, nevera, seguidos del coche - terreno masculino- y sólo después los electrodomésticos que facilitan el trabajo de la mujer. Por su parte, la práctica religiosa manifestada de manera discriminatoria es una de las fuentes de subordinación de las mujeres, advierte Moise (2004: 2), quien considera que para su eliminación se requiere la intervención del estado. La violencia doméstica ha sido y sigue siendo aceptada tácitamente (Pasti 2003: 111), y la violación se reparaba con una boda (aun cuando hubiera sido colectiva). En la Rumanía post-comunista, la violación dentro del matrimonio no es delito y la violencia doméstica en el espacio público se considera una cuestión privada (Woodcock 2004: 4). La primera institución con financiación pública nacida en la transición para mujeres víctimas de abusos 5 (albergue pensado para madres e hijos maltratados en el ámbito familiar), fundada en 1996, tuvo que cerrar sus puertas a los dos años por falta de recursos, permaneciendo como simple centro de asesoramiento. Woodcock (ibid.) señala que "el derecho del hombre a disciplinar a la mujer que ya no cumple el ideal femenino (se ha vuelto demasiado independiente o ha dejado de ser atractiva físicamente) es omnipresente" en la Rumanía del siglo XXI.

Concluye Pasti (2003: 112) que la herencia del comunismo en políticas de género con su duplicidad (minimizando las diferencias generadoras de inferioridad para las mujeres, a la vez que instituían la superioridad de los hombres) se ha mantenido en gran medida tras 1989. Para combatir este legado, se ha de atacar precisamente esa relación de poder hombre-mujer en sus niveles social, individual y familiar, pues según advierte Hurubean (2011: 2) "el desequilibrio de las relaciones de género en la esfera pública y privada pone en tela de juicio la propia legitimidad de la democracia".

\footnotetext{
${ }^{5} \mathrm{Al}$ principio de los años 90 hubo un interés creciente por parte de las ONGs rumanas hacia los problemas de las mujeres. En 1993 había unas 40 organizaciones en este ámbito y en la segunda mitad de la década se mantuvieron gracias a la iniciativa extranjera. La primera iniciativa pública fue el centro piloto de Acción y Apoyo Contra la Violencia Doméstica (Policlínica Titan, Bucarest) bajo la coordinación del Ministerio de Trabajo y Protección Social que sólo funcionó dos años. En el tercer milenio, se fundaron 11 albergues autónomos por iniciativa de ONGs. De manera paradójica, muchos de ellos tuvieron que cerrar, por falta de financiación, a partir de la entrada en vigor de la Ley $217 / 2003$ por la que el Estado asumía la responsabilidad de crear servicios para las víctimas de la violencia (Cf. Antal 2007).
} 
El ideal femenino, como locus de reproducción y objeto sexual, constituye el espacio privado seguro, en contraste con el espacio público que discursivamente se quiere representar como peligroso. De este modo se resta importancia a las agresiones domésticas, pues la amenaza masculina fuera del hogar Woodcock (2004: 10) se atribuye al elemento étnico (gitano), mientras se consolida la dominación del grupo masculino hegemónico.

El ideal de mujer rumana actual es según Rovenţa-Frumuşani la "Cenicienta-superwoman", líder, trabajadora, madre que se deconstruye "infrautilizada en el trabajo" y "actor social callado" (2002: 50). La imagen que difunden los massmedia es, bien la de "mujer objeto" (según observan también nuestras entrevistadas) que retrata a la mujer como objeto sexual (aumentando los índices de audiencia), bien la de mujer "mito de belleza", importado en toda Europa del Este, que promociona a las animadoras jóvenes, altas, delgadas y escotadas como meros objetos decorativos, en total anonimato. En España, advierte Nash (2005: 19), los medios de comunicación ofrecen una visión de género que refuerza los roles tradicionales de domesticidad y objeto sexual cosificado (especialmente en la publicidad) pero esto se agrava con la estereotipación y homogeneización en el caso de las mujeres migrantes. La población femenina rumana sufre las consecuencias de estas campañas de imagen corporal: se incrementan los casos de enfermedades nutricionales, la venta de productos cosméticos, las operaciones de cirugía plástica. La televisión impone estándares distintos (imagen sensual) a las mujeres que a los hombres (puede haber presentadores calvos, bajos y con sobrepeso). Tanto es así que se han llegado a publicar listas de rating de las presentadoras junto con su índice de audiencia y al lado, sus medidas corporales, estableciendo de este modo peligrosas equivalencias, advierte Rovenţa-Frumuşani (2002: 99) refiriéndose a la revista TVmania no 3, 21 de enero 2002, página 16. Alguna de estas presentadoras se convierten durante la transición poscomunista (con el 55\%2\% de la población rumana pasando su tiempo libre en casa, frente a la televisión) en modelos de vida (Marcu 2010: 231).

En opinión de varios estudiosos de la imagen femenina mediatizada, entre ellos Rovenţa-Frumuşani (2002: 114), los medios rumanos no han sabido articular la problemática global de la mujer en la transición. Oscilando entre la imagen de mujer víctima de la violencia (presentada de un modo morboso) y la mujer objeto sexual, no abordan los aspectos graves de la cotidianeidad femenina, como la igualdad de oportunidades, la discriminación, o las dificultades socioeconómicas que las mujeres siguen padeciendo. 


\section{LA MIGRACIÓN RUMANA A ESPAÑA}

Tras unos primeros años esperanzadores (Marcu 2008: 136), por la liberación de la influencia soviética y del aparato represor interno, la euforia revolucionaria da paso a la inseguridad, con un proceso de privatización largo, obstaculizado por la corrupción del aparato burocrático, con un deterioro del nivel de vida que lleva a una tendencia negativa de crecimiento (Băban y David 1996: 164) y con altas cifras de desempleo y la consiguiente pérdida de poder adquisitivo, convirtiendo la migración (Stanek 2009: 225) en estrategia de supervivencia.

Desde 1991 (cuando había 399 rumanos en España ${ }^{6}$ ) hasta 2009 con 798.892, se ha registrado un continuo crecimiento de esta población que, a partir del año 2003, aumenta a razón de 100.000 al año (Viruela 2008b: 170). La cifra de rumanos según el INE a 1 de enero de 2011 es de 864.278. Su distribución ocupa mayoritariamente la Comunidad de Madrid (26\%) y el litoral mediterráneo (36’4\%), siendo sus principales empleos la agricultura, construcción, servicio doméstico (incluyendo el cuidado de personas dependientes y limpieza) y hostelería (Viruela 2010: 161).

Se trata pues de una migración joven, de rápido crecimiento, con una estructura equilibrada en cuanto a sexo, lo cual indica cierto componente familiar; de hecho, Stanek (2009: 247) apunta que son los varones los primeros en llegar, "seguidos en numerosas ocasiones por sus cónyuges o parejas", una migración de fácil integración (debido a la similitud lingüística y cultural, y a la pertenencia a una religión cristiana), una población que procede de todo el territorio rumano, cuyo recibimiento por parte de la sociedad de acogida es en general positivo y cuya movilidad interna y flexibilidad geográfica son altas. De hecho, muchos rumanos llegan a las grandes ciudades y se redistribuyen en busca de trabajo y vivienda hacia municipios rurales incluso de menos de 1.000 habitantes, en los que llegaron a representar un 24\% del padrón de población extranjera (Viruela 2008a: 89). Mientras las áreas rurales españolas acogen a familias rumanas, aparece en el paisaje rumano la "aldea-fantasma" a la que Antohi (2009: 297) alude como espacio de abandono que sólo se vuelve a poblar en verano y durante las fiestas, o cuando los emigrados regresan para pasar las vacaciones o celebrar una boda en el pueblo, no según la tradición local, sino imitando las costumbres adquiridas en el país de acogida y que poco tiene que ver con lo que Diminescu (2009: 52) llama "aldea-pilar», un espacio de resistencia

\footnotetext{
${ }^{6}$ Fuente: Instituto Nacional de Estadística (http://www.ine.es).
} 
durante la dictadura, protagonista de las primeras etapas migratorias externas; lugar simbólico de pertenencia, urbanizada y supraindustrializada durante la dictadura según el modelo stalinista, pero cuya población no se convirtió en clase obrera como planeaba la autoridad estatal, sino que conservó los rasgos de un campesinado, eso sí, abocado a una movilidad forzosa. Esta "aldea-pilar" tiene que ver con la polarización de la migración rumana, señala Diminescu, puesto que es generadora de circulación hacia países y regiones que se repiten, destacando así el componente regional del fenómeno migratorio rumano.

\section{LA IDENTIDAD CORPORAL DE MUJERES RUMANAS EN ESPAÑA}

Featherstone (1991: 187) define el cuerpo como "yo en acción" —el "yo performativo", al que se refiere Martí (2008: 18), cuando afirma que es capaz de gestionar los tres campos de la corporeidad: la apariencia, la exhibición y la impresión. Nos detendremos sobre cuestiones relacionadas con la imagen corporal de las mujeres rumanas antes y después de la caída de la dictadura comunista (1989) en Rumanía, tal y como se perfila en las categorías identificadas en la literatura especializada: indumentaria, cuidado del cuerpo y modificaciones corporales.

\section{APARIENCIA}

La apariencia se refiere a la imagen o presentación corporal (Martí 2008: 18) dentro del valor simbólico del cuerpo y se materializa en acciones — gestos y técnicas corporales (tal y como prefiguraba Mauss) — e imagen, la cual a su vez, consta de tres subcategorías que hemos intentado abordar en nuestras entrevistas y en su posterior análisis. Se trata de:

a) indumentaria

b) cuidado general del cuerpo (donde se incluyen aspectos de higiene, cosmética o tratamiento de las pilosidades)

c) modificaciones corporales

Esteban (2004: 69) parece optar también por una visión triádica de la apariencia, sustentada por ejes como la imagen corporal, el cuerpo individual y el cuerpo social, resaltando la contribución del cuerpo en la construcción social del concepto de persona, en la formación del yo. Le Breton (2002: 82) señala que la manera del individuo de presentarse y representarse da cabida a aspectos como la vestimenta, el peinado, la preparación 
de la cara y el cuidado del cuerpo, de tal manera que el individuo acaba convirtiéndose en su propia tarjeta de visita viviente. La escenificación de la apariencia coloca al ser humano ante la mirada evaluativa (con el riesgo de estigmatización y prejuicio inherente) del otro, que fija una categoría social y moral en función de la vestimenta, la forma corporal o el aspecto de la cara. Featherstone (1991: 187) completa la noción de apariencia con dos subcategorías exhibición e impresión, imprescindibles, no tanto para la afirmación de la posición social, como para la movilidad social, aspecto que se manifiesta en la relación con el cuerpo que las mujeres rumanas establecen en la transición postcomunista.

\subsection{Indumentaria, cabello y adornos en Rumanía y en España}

Según hemos visto, la modalidad de doble vertiente que constituye lo que en las ciencias sociales se denomina "apariencia" es un modo cotidiano de ponerse en juego socialmente a través de un estilo, de una manera de mostrarse. Junto con los cuidados corporales y la preparación de la cara, la indumentaria, el peinado y los adornos constituyen una categoría intrínseca a la manera de presentarse y representarse. En este apartado, procedemos a analizar la información recabada de nuestras entrevistadas, comparando el periodo previo a la caída de la dictadura, con la transición post-comunista y finalmente, con la estancia en España.

\section{Indumentaria}

Sobre la indumentaria que estas mujeres utilizaban en Rumanía para diversas situaciones cotidianas (lugar de trabajo/estudios, la consulta del médico, en el teatro o en una boda) podemos señalar que las migrantes de primera generación, como Ana, recordaban que durante la dictadura los únicos colores posibles eran gris, negro y marrón. En el médico una se ponía lo más bonito y nuevo, y en la escuela el uniforme nacional obligatorio. Tal vez esta imposición (y otras) les hiciera crearse un estilo "serio, clásico, decente" en el que todas insisten, algunas por propia convicción o por "esconder defectos", como Bianca cuyo estilo clásico se debía a no "querer destacar" pues estaba "un poco rechoncha”; recordaba que el teatro requería traje (lo cual suele significar falda o pantalón y chaqueta de corte clásico) y una boda, vestido largo, quizás lentejuelas, siempre "tapando sus defectos", al igual que Florica, que dejó de llevar minifalda cuando empezó a verse "rellenita", mientras que el escote siempre le dio vergüenza (salvo últimamente en España) por su complejo de pechos grandes: "Con doce años, 
ya tenía pechos y mi madre no quería comprarme sujetador (porque aún no tenía la edad), así que llevaba ropa con la que intentaba disimularlos". La censura podía ser también parental como es el caso de Gina quien decía que su madre se encargaba de comprarles la ropa, a ella ya sus hermanas. No hubo conflictos, salvo cuando crecieron. Recuerda optar siempre por la sencillez: seda o terciopelo en una boda, sin brillos ni estridencias; vestido largo sin aberturas o pantalón y chaqueta. No podía llevar minifalda por prohibición paterna, pues incitaba a agresiones. Es parecido el caso de Elena, a quien le hubiera gustado llevar minifalda y escotes pero sus padres no se lo permitían. Otras imposiciones eran de tipo laboral, como la que nos relataba Florica que llevaba bata porque era restauradora de frescos, pero además, al tratarse de monumentos religiosos, la vestimenta por debajo era seria: falda larga, camisa cerrada, los vaqueros no ajustados; si bien era una opción personal, no un estilo obligatorio, todas lo acataban. Hoy le gustaría quizás algún brillo, pero no entonces. Su estilo era clásico. En España se ha modernizado, pero sigue siendo clásico. Lo cierto es que el estilo que prevalece en todas estas narraciones es el "serio" con una carga de pudor y miedo a destacar o llamar la atención (lo cual, por otra parte, en el régimen totalitario se extrapolaba a todos los ámbitos de la vida), exceptuando quizás a Ioana, quien confesaba que su ropa era siempre de calidad y su estilo elegante, atrevido, con escotes, o minifalda. También "llevaba aberturas detrás, en el lateral e incluso delante».

En los testimonios de las mujeres de más edad se denota una tendencia hacia lo "clásico y decente" y un respeto casi ritual al médico; por ejemplo, Corina señalaba que no iba al teatro "por pertenecer al rito adventista", pero en otro tipo de actos sociales, su estilo era "femenino y elegante" mientras que en la consulta, "siempre bien vestida, arreglada y limpia" (Gina añadía: "Como en la iglesia"), por su parte, el ámbito laboral requería sobriedad, nunca prendas sport (no siquiera calzado). Las informantes más jóvenes no consideran la situación de la consulta distinta a cualquier otra de la vida diaria, lo cual confirma que, sobre todo antes de 1989, la figura del médico gozaba de gran autoridad en la sociedad rumana. La segunda generación de migrantes rumanas (mujeres que no emprendieron ellas mismas la aventura migratoria, sino que siguieron a sus padres) es representada por dos entrevistadas, Dana y Elena. Para ir al instituto en Rumanía, Dana se vestía de un modo "serio", con "pantalones decentes" y chaqueta, "no como en España". Quedaban descartadas las estridencias para las bodas o los tirantes para lo diario. Bastante parecidas son las opciones de Elena quien para estudiar llevaba lo más cómodo, simple y clásico. Ninguna diferencia en el médico. En una boda se hubiera puesto algún adorno, aunque confiesa no haber ido casi a bodas, pues «el tiempo en Rumanía fue un tiem- 
po muerto". Le encantaban los escotes y también los brillos, pero sus padres no le permitían llevar falda corta, escote, o uñas largas.

Además de la (auto)censura en la vestimenta, también observamos una representación bastante represiva de los cuerpos con "kilos de más" los cuales, según el ideal estético colectivo, están penalizados por la sociedad, pues varias entrevistadas recuerdan haber tenido complejos y haber adoptado medidas de autocensura (taparse) y, como veremos más tarde, casi todas se someten a regímenes de adelgazamiento.

Se desprende de estos testimonios una preocupación por la aceptación por parte del grupo ("después de bodas y entierros siempre hay comentarios; es muy importante cómo te ven los demás", decía Ana) y una búsqueda de explicaciones metafóricas ("los que somos del este, decía Elena, como tenemos menos sol, necesitamos que la ropa lleve brillos"). Vemos también un conflicto generacional (latente en el caso de Gina cuya ropa la escoge la madre, o abierto, o en caso de Florica, basado en la contradicción entre su edad física, con el desarrollo de sus pechos, y su edad cronológica, a la que la madre se aferraba cuando decidía que aún "no tenía edad para sujetador"). Finalmente, se vislumbra la existencia de estereotipos interiorizados sobre ciertos oficios, como el que se desprende del enunciado de Ana, "Aunque estudiara coreografía, eso no significaba ir desnuda por la calle». Su estilo cotidiano era modesto y decente como correspondía a una hija de agricultores sin medios: "tenía ese pudor del que estaba orgullosa" y veía como un signo de respeto el no exhibirse.

El estilo de vestir de las mujeres entrevistadas se ha modificado prácticamente en todos los casos con la experiencia migratoria, aunque no siempre de manera consciente. Cuatro de las entrevistadas advierten mayor apertura, libertad y desencorsetamiento de los prejuicios, evaluación o censura del grupo social, que se traduce en colores más alegres, escotes más atrevidos, cortos más pronunciados. Por ejemplo, Bianca decía haber superado todos los complejos en España; ahora lleva minifaldas, blusas escotadas, pantalón corto; no presta tanta atención, pues «es un mundo muy democrático y la gente se viste relajadamente. Creo que aquí nadie nos juzga porque aquí somos todos iguales, ésta es la sensación que tengo. En Rumanía te miraban y te clasificaban; si vestías algo más estridente, enseguida eras vulgar [...] si mi madre me viera ahora, con minifalda, me llamaría la atención". Dana afirmaba claramente que su estilo de vestir ha cambiado mucho con su llegada a España. Elena contestaba de manera concisa: "en España me siento más libre». Florica estaba embarazada en el momento de la entrevista, pero excepto en ese periodo, viste ropa ajustada y colores muy claros. "Antes, los colores eran negro, blanco, marrón y gris; ahora me pongo amarillo, azul, rosa, morado, que no me atrevía a ponerme en la vida. 
Llevo más escote, vestidos de tirantes. El día de la boda civil llevaba un vestido con toda la espalda al aire y mi tía iba loca detrás para taparme....

Tres informantes contestaban que el cambio se produjo hacia un estilo "más práctico", como en el caso de Ioana que afirmaba no poder mostrar su feminidad en España tanto como solía hacerlo en Rumanía, por la edad, pero sobre todo porque las españolas visten sport, aunque reconocía que lo mismo había pasado en su país de origen tras la caída del régimen comunista. La gente «tiene un aspecto más normal, más real, más cómodo, más práctico". Durante la dictadura, recordaba un estilo de vestir demasiado formal o artificial. Había ideas preconcebidas sobre el grupo social, "tenías que tener buena apariencia y eso incluía tacones altos, ropa cara, trajes de chaqueta y siempre algo nuevo". En la enseñanza se requería lo clásico, "por ejemplo la festividad de fin de curso con los padres de alumnos era algo serio y debías vestir muy sobrio". En el caso de Ana, el cambio provocado por la experiencia migratoria se tradujo en un estilo "menos competitivo". Al trabajar de empleada de hogar vestía modestamente, pues no había venido a España "a competir con las señoras de aquí", lo cual evitaría conflictos, incluso le brindaría una relación casi de amistad. Hay dos grandes prioridades en su vida muy por delante del aspecto físico: construir una casa y ver mundo. En el caso de Gina, el cambio desemboca en un estilo "más descuidado". Gina recordaba que al poco de llegar a España tuvo a su hijo y abandonó los cuidados corporales. Por otra parte, su marido no quería una persona que dedicase demasiado tiempo a los aspectos superficiales: "prefiere hablar, que tengamos una comunicación". Confesaba que aunque nunca vestiría provocadoramente, le habría gustado ser más elegante. Finalmente, sólo una de las mujeres consideraba que había mantenido el mismo estilo, aunque con la coletilla "adaptándolo a la ropa de aquí". Corina confesaba que su estilo no había cambiado en absoluto, seguía siendo elegante y clásico, sin llamar la atención: "mi principio, cuando me pongo una prenda, es ver si esa prenda me representa".

\section{Adornos y accesorios}

Un aspecto esencial de la apariencia corporal son los adornos y accesorios, entre ellos el oro, una constante que aparece como signo de estatus social, que no sólo ha de ser mirado como un valor, sino que conlleva un ritual (lo compra la madre, o el marido, como en el caso de Ana, Florica o Gina), y la mujer es apta para llevarlo a partir de cierta edad. Asimismo, la alianza como signo de los votos matrimoniales no falta en ninguna de las narraciones de las mujeres casadas. Otro elemento recurrente es la cadena con la cruz, un elemento estético dotado además de un significado trascen- 
dental, pues lleva la bendición que pone en contacto al portador con lo divino, como recalcó Ana: "No llevaba accesorios; la alianza y un anillo (regalo de su marido), o una cadena con crucecita bendecida en la iglesia. Siempre de oro". En España no lleva nada por no llamar la atención. Salvo Corina quien rechaza los accesorios: "en mis tiempos la gente era de otra manera; nos agarrábamos con fuerza a las tradiciones", el resto de entrevistadas muestra una tendencia clara hacia el oro durante su etapa en Rumanía y una versatilidad (que incluye la bisutería-fantasía) en España. Si tuviera dinero, Dana se compraría oro blanco. En España, a diferencia de su país, sí lleva adornos, pero muy discretos, observables "sólo por un ojo experto". Elena recordaba que los pendientes eran pecado: "me crié en una cultura protestante donde era pecado respirar, en general todo era pecado. Aquí me pongo casi de todo, algún collar finito, alguna pulsera discreta, poquito, tampoco soy gitana". A los 20 años la madre de Florica consideró que ya tenía la edad y le compró "una cadena con cruz". En España se compra bisutería, que lleva en el trabajo. Antes llevaba cosas más discretas; ahora más variadas, que se pone en función del estado anímico. Ioana recuerda que en Rumanía la bisutería no se llevaba, se consideraba de mal gusto; en España lleva plata incluso bisutería, porque tiene la posibilidad de cambiarla a menudo y combinarla con la vestimenta; siempre por consideraciones económicas.

\section{Cuidados del cabello}

En cuanto al cuidado del cabello, en su país de origen recurrían a los servicios de corte, peinado, permanente, teñido, mechas, y otros tratamientos, gran parte de los cuales no pueden permitirse en España. Ana recuerda que en su adolescencia llevaba moño por razones de eficiencia y si a algunos no les gustaba "eran libres de mirar para otro lado" ${ }^{7}$. Actualmente se tiñe sólo para tapar las canas, "nada historiado". En Rumanía iba a la peluquería antes de una boda o bautizo. En España no ha ido nunca a la peluquería, se lo corta y se lo tiñe ella misma. Bianca lleva el cabello recogido, por cuestiones de trabajo (limpiadora) y se lo suelta en ocasiones especiales. Al tenerlo largo, iba poco a la peluquería; en España iría pero no puede, salvo en algunas fechas señaladas; normalmente se lo tiñe y arregla sola. A diferencia de Ana y Bianca, Florica cuya obsesión era ser rubia con ojos azules, iba mucho a la peluquería en la época de transición que

\footnotetext{
${ }^{7}$ Este enunciado nos hace pensar en uno de los preceptos (pelo largo, suelto) del ideal de belleza femenino rumano que, en efecto, se confirma en las narraciones de otras entrevistadas.
} 
coincide con su inserción laboral y cierta holgura material, al igual que Ioana que llevaba el pelo corto y mechas e iba a la peluquería cada dos semanas, tanto antes como después del cambio de régimen. Tanto las que frecuentaban poco la peluquería como las que iban a menudo, han dejado de hacerlo en España. No obstante, recurren a estos servicios para aquellos cuidados que no pueden efectuar ellas mismas mientras aprenden a hacerlo, pero ninguno de los testimonios habla de renuncia.

\subsection{Cuidado general del cuerpo. Cosmética y pilosidades}

Dentro de la misma esfera de los cuidados corporales, además de la vestimenta, adornos y cuidado del cabello, hay otro apartado de interés que es la cosmética (donde incluimos los tratamientos de pilosidades, manicura, pedicura, productos cosméticos y maquillaje), a lo que Le Breton se refería como mantenimiento público de la corporeidad frente a la higiene privada (2002: 60). De nuevo observamos que estas prácticas persisten en situación migratoria, aunque en menor medida, pues gozaban de menor arraigo que los cuidados del pelo. Si los medios económicos no les permiten visitar a la esteticista, esos cuidados se los administran ellas mismas, pero ninguna de las que tenían este hábito en su país de origen, baraja renunciar a él pese a las dificultades materiales.

Ana se maquillaba a diario en Rumanía, mientras que en España lo hace esporádicamente y se hace ella misma la depilación, incluidas las cejas. Bianca recuerda lo importante que era la cosmética para ella, utilizaba cremas por su cutis seco, se hacía la manicura y pedicura regularmente y le gustaba pintarse las uñas; las piernas siempre depiladas "como cualquier mujer", añade. En España se lo hace todo ella misma. Corina considera la cosmética necesaria, pero en Rumanía no iba mucho a la esteticista; se hacía las uñas, se depilaba; cejas y maquillaje menos, pues trabajaba en una planta de electricidad con horarios extremos y no le quedaba tiempo. En España, decía, "lo mejor es agua y jabón". Dana insiste en la necesidad de adquirir productos cosméticos de marca. Elena consideraba importante la cosmética, aunque no iba a la esteticista en Rumanía porque no se fiaba. Se lo hacía sola o con ayuda de la tía. En España se maquilla a diario, hasta para estar por casa y sigue con el miedo a coger enfermedades de piel. En cambio Florica iba muy asiduamente a la esteticista por los precios asequibles y porque no sabía arreglarse sola. Le gustaba maquillarse ya a los 14 años con mucho colorete y mucha sombra azul y verde, hasta que en el barrio una dependienta la avergonzó y dejó de pintarse. En España, si el sueldo se lo permite, va una vez al mes. Gina se depilaba en casa, no iba 
a la esteticista. Ahora va cada vez que viaja a Rumanía, se depila y se hace las cejas. Por regla general no usa maquillaje, porque no le queda bien: "Recuerdo que me maquillaron en mi boda y parecía más vieja, por los colores oscuros. De todos modos, no me molestó; para mí era importante la boda en sí no el aspecto". A Ioana le importaba mucho la cosmética: "antes era inconcebible. Nunca habría ido ante mis alumnos con estas manos". Iba a la esteticista regularmente para depilaciones y cejas, y se maquillaba a diario. En España se maquilla menos y se lo hace todo sola.

\subsection{Modificaciones corporales y cambios de estilo}

Además de la carga estética, erótica o de afirmación personal, las modificaciones corporales pueden tener una carga subversiva, puesto que el cuerpo es, además de agente, un objeto social, un pivote para conciliar la identidad social y la individual, ese juego dialéctico entre el deseo de afirmación de la individualidad y el de adscripción a un grupo (Martí 2008: 101), por lo que los ámbitos de poder siempre le han prestado la máxima atención; prueba de ello son las políticas de humillación y enajenación corporal sufridas por toda la sociedad rumana, pero especialmente por las mujeres durante el régimen totalitario.

La modificación no es fruto del azar, es una acción finalista, en la que el yo performativo calibra qué puede hacer con su cuerpo para conseguir algo de la sociedad. La literatura especializada distingue las modificaciones corporales "bruscas", es decir las de interferencia externa y resultado inmediato (como el tatuaje, piercing, inyección de silicona o botox, liposucciones y cirugías plásticas), de las "suaves" que no cuentan con una interferencia externa (o ésta es mínima) y cuyo resultado es apreciable a medio o largo plazo, como aquellas técnicas pertenecientes al body art que no suponen un cambio permanente (pintura corporal, henna, peinados y postizos) o prácticas de fitness o bronceado con rayos UVA. Las "inscripciones corporales" a las que alude Le Breton (2002: 62) como sustracción de un fragmento de cuerpo, marcas profundas en la carne, inscripciones en la piel, modificaciones en la forma del cuerpo, uso de joyas rituales o alteradoras, se resumen hoy en día en las sociedades occidentales a versiones "atenuadas" del marcado corporal, tatuajes o maquillajes. Las modificaciones corporales, cuyos motivos son divididos en cinco categorías: estética (mejora del capital corporal); individualista (signo de unicidad); grupal (signo de pertenencia); religiosa (signo de sometimiento a una creencia); y controladora (propia de la relación de poder), pueden dar cierta impresión de libertad, aunque Martí (2008: 117) advierte que modificamos a nuestro libre albedrío 
el cuerpo, pero siempre en relación con la imagen que queremos proyectar ante la sociedad.

La costumbre de hacerse poner dientes/muelas de oro constituye una tradición bastante enraizada en las sociedades del este de Europa (y por ende también Rumanía), sobre todo desde finales del siglo XIX hasta la primera mitad del XX. Aunque ha ido desapareciendo paulatinamente en la segunda mitad del siglo pasado, se mantiene en algunas zonas o comunidades étnicas y en determinados estratos sociales. Esta modificación corporal nos proporciona información acerca de la construcción social de nuestras entrevistadas, en relación con el marco geográfico de su procedencia y ámbito familiar. Acerca de la opinión que les merece esta práctica, la explicación de sus razones y la experiencia personal en este sentido (si tienen o han tenido una pieza de oro en su dentadura y si, en caso de tenerla, la mantendrían en España), observamos una unanimidad asombrosa en cuanto a la adscripción a la población gitana de la costumbre de la funda dental de oro, asociándose sin embargo este hábito a la ostentación, señal de riqueza, signo de bienestar. Bianca, en Rumanía, se tuvo que implantar una pieza por enfermedad y por recomendación médica recurrió al metal precioso. En aquella época no era mal visto, aunque ahora en España querría cambiarla por porcelana pues "es anti-estético". Pero el resto de las mujeres entrevistadas descartan totalmente esta posibilidad. No recuerdan que hubiera dientes de oro en sus familias. Ana cree que es costumbre gitana; "ellos se implantaban el oro que tenían para que no se lo robasen". Por su parte, Corina no recuerda una tradición en su zona. Opina que es "una manera de los gitanos de tener el oro siempre con ellos" y no se le ha pasado nunca por la cabeza ponerse algo así en la boca. Dana nos explicaba: "He visto en mi zona dientes del color del oro, aunque puede que fuera simple latón. Son los gitanos ricos los que los tienen. A veces se les desentierra para robarles los dientes [...]. Se los ponen para ostentar; no es estético, pero muestra lo rico que eres. Una persona normal, aun teniendo oro, no se lo pondría en la boca" y añade que tuvo una pieza de metal en la boca que se quitó. A su vez, Elena recuerda tener unos vecinos gitanos "de los de faldas largas" que sí llevaban dientes de oro; supone que es por tradición, "ellos son así, o tal vez no tengan otros materiales. O puede ser una manera de guardar el oro, pero en todo caso, peligrosa". Florica recuerda esta tradición en su zona: "en mi familia no sé, pero a mí me pusieron un diente de un metal amarillo no de oro y me daba vergüenza sonreír". Lo detesta por ostentoso y por su asociación con los gitanos. Finalmente, Gina recuerda que en su zona se veían bastantes dentaduras con oro. Muchos en Bucarest, pero en su familia no: "El oro es para ostentar, es signo de riqueza. Nunca me lo pondría en la boca. Jamás". Lo mismo afirmaba Ioana en 
cuya zona de origen no había tradición, salvo "alguna muela, pero a la vista ni hablar; los dientes de oro sólo los llevaban los gitanos. La gente de buena calidad se ponían oro porque era más sano, duradero, se mantenía mejor, pero que no se viera". En cambio, "los gitanos y la gente del sur, como señal de bienestar o por esnobismo, se ponían los caninos de oro". Es interesante ver cómo este estereotipo o incluso prejuicio actúa hasta el extremo de que, incluso las personas que sin ser gitanas hayan tenido tales piezas en su dentadura, afirmen que es una costumbre propia (y casi exclusiva) de los gitanos ${ }^{8}$. La tendencia general de la sociedad rumana actual está dominada por estereotipos negativos contra los gitanos. En 1996 el término ţigan es sustituido por rrom en los documentos oficiales. Hubo polémica en la prensa y en la calle porque el término en su forma plural guardaba demasiado parecido con "rumano". En el 2000 se adopta como término oficial rroma. Ninguna de nuestras entrevistadas (las que se refieren a costumbres gitanas) lo hacen con el término oficial, sino con el de siempre, țigan, con carga negativa semántica, incluso en oposición con «la gente de buena calidad".

Ante la opción de cambios corporales de mayor envergadura, como por ejemplo una intervención de cirugía estética, las respuestas son semejantes y aparece alguna reacción curiosa como la de Bianca, de obviar su tatuaje en la narración, si bien es visible en su tobillo, tal vez por discordar con sus afirmaciones a lo largo de la entrevista. La mayoría de las entrevistadas reconocen hacer gimnasia (salvo Corina y Elena), a veces junto con dietas (Gina) y algunas acusan haber engordado en España (Ana, Bianca, Florica). Por una clínica sólo ha pasado Dana (para una depilación láser). Dos mujeres reconocen que modificarían su cuerpo si tuvieran los medios materiales: Elena (piercing de diamante en el ombligo) y Florica (reducción de pechos, pues recuerda una adolescencia acomplejada). El resto son muy categóricas en el rechazo. Y es que en la imagen corporal general, estas mujeres parecen mantener mayoritariamente un estilo "totalmente rumano", como es el caso de Gina y de Ana, o un "rumano adaptado", con variaciones, como es el caso de Bianca o el de Ioana, quien afirma que su estilo

8 Según Woodcock (2004) la etnia gitana, formada por siervos inmigrados que llegan al territorio rumano en el siglo XV, es catalogada por las élites rumanas (que, a su vez, se consideran civilizadas por pertenecer al grupo etno-nacional europeo) como "incivilizada, sin educación y nómada". En 1856 es abolida la servidumbre pero siguen siendo percibidos como una etnia distinta de la rumana, resultando en una marginación económica, política y social. A partir de 1989 se intensifican las tensiones creadas por el etno-nacionalismo rumano y los discursos de la sociedad civil que ha de negociar su identidad europea con vistas a la integración. 
general no ha variado con la migración, pero ello se debe a su procedencia de la región rumana de Bihor, a pocos kilómetros de Hungría, muy occidentalizada en ropa, en pensamiento y en forma de vida, por lo que no notó diferencia cuando llegó a España. Lo que sí ha cambiado es su estilo en el trabajo, ahora más sport y con pantalones, debido a que trabaja con niños de menor edad, mientras que en Rumanía iba mucho más elegante. Algunas optan por un "estilo combinado", como Dana, quien afirma que el suyo es entre español y rumano pues lo importante es que le quede bien. Le gusta de los españoles el hecho de que "sean más relajados". En Rumanía, la vestimenta "era más sobria, chanclas sólo en la playa; si no, te preguntaban si no tenías con qué calzarte. Aquí es más fácil, más relajado"; al igual que Corina cuyo estilo es combinado pero prima siempre su gusto, no el impuesto por los demás. A su vez, Florica recuerda que su estilo, el primer año fue totalmente rumano, la ropa la traía de casa; luego poco a poco empezó a comprar ropa, a mirar y a combinar: "mi estilo no es típicamente español, pero tampoco rumano ya". También hay quien (Elena) opta por un estilo suyo personal, manteniendo una línea clásica, si bien señala que le gusta mirar las pasarelas. Ninguna de las entrevistadas parece haber adoptado un estilo considerado por ellas "total o marcadamente español".

En cualquier caso, debe destacarse que casi todas las informantes consideran que deben mostrar su feminidad en sociedad, pues, salvo Gina que contesta negativamente, siete de las ocho entrevistadas han dado un "Sí" categórico (en el caso de Ana, Florica y Elena), y con comentarios añadidos en el caso de Bianca (quien considera el pelo largo, la delicadeza y cuidarse, como los tres pilares de la feminidad). Corina sugiere una separación de prendas desde la infancia, es decir "a las chicas vestirlas con faldas". Dana ve que las niñas están en desventaja, ya que la censura parental es más estricta con ellas, y por último, Ioana lo ve importante para la imagen y para sentirse bien.

\section{Corporeidad y totalitarismo}

El afán de regulación y control social de la población/individuo a través del cuerpo se ve claramente en el funcionamiento de instituciones como hospitales, escuelas, ejército y tiene como fin último tener sometidas a las personas productivas (Foucault 2003: 82). Hay un proceso general de control de los cuerpos o de control de la sociedad a través de los cuerpos (véase la política reproductiva y punitiva en este sentido en Rumanía bajo el régimen de Ceauşescu), control que según Foucault se puede realizar de manera soslayada (publicidad, massmedia) o agresiva (a través de mecanismos 
opresivos y represivos, como es el caso de Rumanía donde, para la aplicación y sanción del decreto 770, el poder actuaba en los hospitales rumanos a través del fiscal y policía, presentes en cualquier presunto intento de interrupción de embarazo).

Como Esteban (2004: 69) advierte, si bien cada sujeto de nuestra sociedad es una entidad individual delimitada por las fronteras del cuerpo, muchas entidades corporales impuestas como ideales vienen definidas de antemano por las estructuras de poder y envasadas por las industrias de consumo, belleza o publicidad, donde interviene otra combinación paradójica consustancial: la incitación al consumo, y su control, también comercializado, aunque en productos de formato distinto.

\subsection{Uniformidad, censura, resistencia}

A continuación, nos ocuparemos más en detalle del periodo totalitario, más exactamente del segmento de su última agudización (los años de 1980) y de la etapa post-comunista de los 90, época de transición y mirada hacia occidente, al final de la cual algunas de las mujeres entrevistadas, deciden emprender la experiencia migratoria.

En primer lugar, nos interesaba ver cómo recordaban nuestras entrevistadas los años del comunismo (¿especialmente anti-femeninos?, ¿uniformizadores?), con ropa de fabricación nacional, cumpliendo unos determinados clichés importados de otras naciones más avanzadas en el grado de homogeneización (Unión Soviética, China, Corea), o al contrario, si recurrían a mecanismos de resistencia: la confección casera con patrones de revistas como "Burda" o "Neckermann"; el envío de ropa occidental por paquete $^{9}$ de familiares o amigos; la obtención gracias al estraperlo de artículos de contrabando como los vaqueros o las zapatillas de marca. De aquí se desprendía otra cuestión de gran interés: cómo veían nuestras entrevistadas la obligatoriedad del uniforme en colegios e institutos (el de diario y el de gala con insignias y galones de buenos resultados) y el uniforme militar para las universitarias a las que se instruía para la defensa nacional un día a la semana a lo largo de los estudios. ¿Qué lugar ocupaba el traje popular tradicional? Por último, queríamos observar si nuestras entrevistadas eran

\footnotetext{
${ }^{9}$ Cabe mencionar aquí el estatus que suponía vestir "del paquete" (o sea de los paquetes que amigos o familiares establecidos en occidente enviaban). Obviamente, esto tenía una contraprestación: la investigación por parte del sistema opresivo. En todo caso, vestir con prendas del exterior, siguiendo la moda occidental era una manera de resistencia, y suponía marcar diferencias, gozar de la admiración (y envidia) del grupo.
} 
conscientes de la censura aplicada al cuerpo (sobre todo femenino) en el cine de la dictadura y si para ellas hoy en día el cuerpo se exhibe más y si la mujer se afirma a través de él.

La cuestión del uniforme fue objeto de debate. Salvo Corina que adoptó la postura de los padres en lugar de la del adolescente: "no veo mal el uniforme, menos quebraderos de cabeza para los padres, daba equilibrio", el resto vieron la estética de la época (incluido el uniforme) anti-femenina, plana, uniformizadora, gris. Bianca por ejemplo, la recuerda fea y anti-moda, y tiene todavía hoy presente haber tenido problemas con el flequillo por el que casi la expulsan.

Dos matizaciones llaman la atención. Primero que la mujer podía ser llamada "puta" por la calle por vestir fuera de la uniformidad. Como recuerda Gina: "en la escuela si te salías del uniforme, te amonestaban públicamente, era embarazoso; en la calle podías oír comentarios de tipo mira esa puta. Segundo, la estructura masculina que detentaba el poder podía sancionar a una mujer por llevar minifalda en un marco formal, tal y como relató Ioana: "Los hombres tenían los puestos de mando y los siguen teniendo; por supuesto que era de mal gusto ir a una reunión de trabajo con minifalda, pero es que además, te sancionaban profesionalmente y en el partido también. Era un estilo anti-moda. Creo que se debía quizás a la mujer del Presidente, a Elena Ceauşescu...".

Sobre el tipo de ropa que llevaban las mujeres en la dictadura, vemos que la mayoría compraban confección socialista y los que se escapaban a esa estética eran quienes, por trabajo, salían del país. Ana recuerda: "me compraba la ropa en el extranjero; yo era de los que podían salir, para mí era maravilloso, podía comprarle a mi hermano un par de vaqueros todos los años. Pero tenías que ser la mejor, la lucha era muy dura para poder salir y luego te lo tenía que aprobar el Secretario del Partido, el Presidente del Sindicato, el Secretario de Juventudes. Si tenías un fallo en el expediente, ya no salías". También evadían la estética impuesta quienes podían permitirse una modista, por su mayor poder adquisitivo, como afirma Ioana: "tenía mi costurera. A veces incluso, iba a la Casa de la Moda ${ }^{10}$, me lo podía permitir. De hecho me permitía muchas más cosas que aquí".

Hubo casi unanimidad al discutir la importancia del cuerpo frente al intelecto (el cual parecía primar antes de 1989 en la imagen de respetabilidad social) mientras que en la transición impera la percepción de supremacía corporal, salvo Elena que considera que siempre fue así, sólo que

\footnotetext{
${ }^{10}$ Versión comunista de los diseñadores de moda. Organizaban una especie de pasarelas con colecciones distintas a la confección de masas y sus precios no estaban al alcance de todos.
} 
de manera enmascarada, hipócrita durante el totalitarismo. El resto de las informantes corroboraron que la mujer rumana se afirmaba a través de su cuerpo y lo cuidaba más. Emergió la idea de mujer rumana con fama de prostituta, en dos testimonios. Elena, quien opina que la mujer rumana actual exagera exhibiendo su cuerpo: "esto no significa que se cuide más, sino que se está construyendo una imagen de (tal y como la considera Europa) puta. Y no está bien. En Bucarest, vas al metro y encuentras revistas con mujeres desnudas". Según Ioana: "se afirma incluso demasiado: se pasa de un extremo a otro. Se exagera. Exhiben demasiado su cuerpo. Luego el 80\%90\% de las chicas que vienen aquí a prostituirse son rumanas. Lo que más hacen, he oído, es gimnasio, sauna, se retocan los senos y los labios». En su análisis sobre corporeidad en el caso de las modelos profesionales, SoleyBeltrán señala que son mujeres "elevadas" con éxito profesional, mientras que las prostitutas son mujeres "caídas" (2005: 432), una metáfora bidireccional que en Rumanía no está del todo delimitada.

De estos testimonios se desprendió que el concepto de éxito profesional y las oportunidades en el mundo postcomunista, estaba ligado a una imagen corporal bella (según un determinado canon o ideal de esa comunidad o grupo social), y también provocativa, exhibiéndose en exceso. En efecto, tal y como señala Marcu (2010: 229), en la transición poscomunista rumana aparecen nuevos valores y modelos alternativos que pretenden sustituir a los tradicionales, debido a un trasfondo de desconfianza causado por la corrupción de las élites. Emergen, según esta autora, modelos como el de "éxito en la vida" que convierte las relaciones matrimoniales en un "intercambio ventajoso" en el plano individual y social, cuando el escenario de realización personal, con sus pilares tradicionales (educación y familia) pierde fuerza y entran en juego elementos como la belleza.

Es interesante observar que durante la dictadura, generalmente no se recurría al traje popular tradicional, a no ser que se obligara a ello. Y el uniforme diario (colegio, instituto), exceptuando alguna consideración en pro de la aparente igualdad de medios económicos, se consideraba traumático o al menos, portador de restricciones y símbolo de toda una estética estatal impuesta y anti-femenina. Otra suerte corría el uniforme de pionera $^{11}$ (para ocasiones de gala) que a la mayoría de las entrevistadas les

${ }^{11}$ La Organización de Pioneros era previa a la de Juventudes Comunistas y comprendía escolares de edades entre los 8 y los 14 años, desarrollando sus actividades en el colegio en paralelo a la enseñanza. El traje de pionero era de gala, distinto del uniforme escolar diario y su símbolo más reconocible era la pañoleta roja al cuello. Los pioneros formaban en cuadrilátero, izaban y saludaban la bandera y tenían comandantes de grupo, de destacamento y de unidad. 
trae buenos recuerdos (relacionados con su colorido más optimista y con una edad más temprana en la cual todavía se creía en la competición, siendo un orgullo ostentar el cargo de "comandante de destacamento"). El uniforme militar propio de las estudiantes universitarias, al contrario, se asocia al odio hacia el sistema. Un testimonio radiografía del uniforme en distintas situaciones es el de Ioana: "el uniforme era traumático a veces. Me di cuenta más tarde. Tuve problemas con la cinta de pelo. Me llegaron a bajar la nota por eso. Odiaba esa cosa blanca en la cabeza. No me dejaban el flequillo. Sí era anti-feminidad. No me trae buenos recuerdos. La preparación militar, el uniforme y todo lo demás era traumático; marchando con un calor de más de $30^{\circ}$, cantando. Para morirse. Cantábamos y sólo sentíamos odio. Era detestable, grotesco. Nunca llevé traje popular. Crecí en zona magiar; soy rumana, pero rodeada de húngaros. Luego me casé y me fui a la ciudad".

Hubo unanimidad también en lo que respecta a la censura del cuerpo en cine y TV, con dos matizaciones de Ana y Corina en cuyas respuestas parece entreverse cierta nostalgia por la "moral socialista" que "te decía por dónde ir" o que "no dejaba a las mujeres salir de cualquier manera". El elemento recurrente de la esposa del dictador, cortando cabezas y actuando como inquisidora, vuelve a estar presente en las respuestas de Gina, quien habla de la censura en estos términos: "más en el cine que en los libros. Se censuraba no tanto la imagen del cuerpo, sino la imagen del cuerpo mostrado, visible. Se decía que era el gabinete № 2, o sea ella, la mujer de Ceauşescu, que era fea y tenía manía a los cuerpos hermosos". Por su parte, Ioana tiene un recuerdo muy parecido: “tenían normas, reglas, muy rígidas, principios morales y se metía mucho su mujer; se dice que muchas películas, antes de salir al mercado, eran visionadas por ellos dos y ella era la que cortaba cabezas. Mucha censura".

El hecho de que nuestras entrevistadas aludan de manera recurrente a la figura de Elena Ceauşescu no es casual. Cuando asume el poder, Nicolae Ceauşescu se presenta ante el pueblo como un líder joven, valiente en las relaciones externas y abierto para el diálogo con la sociedad. En 1973, según señala Olteanu (2004) Nicolae Ceauşescu era el prototipo del hombre de éxito y un año más tarde, pasa de la fase autoritaria a la oligárquica, incluyendo en la élite dirigente a su mujer que empieza a gozar de elogios parecidos, aunque su adulación está subordinada al papel del líder. Elena Ceauşescu pasa de ser la política destacada, a ser paulatina y acumulativamente mujer modelo, científica de prestigio, revolucionaria bistórica, intelectual pacifista y finalmente beroina, aunque en los 80 el pueblo se refería a ella como gabinete número dos. En términos concretos, en 1985, controlaba la ciencia, tecnología y educación en el país. El sistema autárquico (no en solitario como otros dictadores, sino en pareja) hace imposi- 
ble la cooperación con occidente e incluso con los otros estados de la Europa del Este y obviamente, la aparición de centros de autoridad alternativa dentro del país. Con esa estampa de igualdad política entre los cónyuges (la leyenda urbana señalaría la superioridad de ella), Rumanía vivía una saturación propagandística inversamente proporcional al estándar de vida en continuo deterioro (racionamiento de los alimentos, falta de agua y de electricidad, eliminación del único día libre semanal), según observa Massino (2004), de ahí la recurrencia del personaje de Elena Ceauşescu en las narrativas de nuestras mujeres, recordando la literatura popular rumana plagada de personajes maléficos femeninos: arpías, brujas y malvadas madrastras se reencarnan en la imagen de la "primera camarada".

\section{CONCLUSIONES}

Esta investigación sobre la identidad corporal de las mujeres rumanas permite extraer algunas conclusiones.

En primer lugar, la imagen corporal que estas mujeres construyen durante la última década del comunismo se caracteriza por un estilo, sobrio en el trabajo, muy clásico en los encuentros sociales, elegante, sin exageraciones en eventos afectivos y con la ropa mejor y más nueva en el médico. El uniforme es recordado por la mayoría de ellas como anti-femenino y causante de problemas, excepto el de pionera por relacionarse con una fase infantil temprana y con un mecanismo recompensatorio; los adornos parecen resumirse a la alianza para las casadas y la cadena con cruz (signo de una fe inhibida antes del 1989 y exacerbada después), prefiriéndose siempre el oro. El cuidado del pelo se realizaba con cierta frecuencia y primaba el pelo largo como marca de feminidad. La estética de cara y cuerpo, incluido el tratamiento de pilosidades, completaba los cuidados corporales que en el caso de algunas de las mujeres entrevistadas, incrementaron tras la caída del comunismo, porque "seguía siendo barato" y su estatus se lo permitía, incluso exigía; excepción hacen las entrevistadas pertenecientes al rito adventista. La llegada a España supuso algunos cambios en la apariencia de estas mujeres, si bien su identidad corporal sigue intacta según parecen asegurar. Casi todas afirman mantener un "estilo rumano" en su indumentaria, aunque, a medida que prosiguen en su narración, señalan adaptaciones vestimentarias a las prendas que se encuentran en las tiendas españolas, un cambio radical en el colorido, en los escotes y cortos, en la aceptación (incluso preferencia) de la bisutería como alternativa al oro, entre otras cosas. Todas recalcan el sentido de libertad, desencorsetamiento, relajación en la imagen corporal 
y en el comportamiento que la experiencia migratoria y la adaptación al contexto social español ha acarreado.

En segundo lugar, las mujeres rumanas trasladan a su contexto diaspórico lo que la sociedad rumana actual parece haber interiorizado y que llamaríamos un intento de mejora del capital corporal (sea estéticamente, sea mediante la gestión del estado saludable, o la imitación artificial de la naturalidad corporal). No se registran testimonios que indiquen modificaciones corporales mayores (cirugía) y tampoco tratamientos laser en clínica, excepto en un caso. Lo máximo a lo que se someten son a las dietas y alguna, ocasionalmente, a la gimnasia, aunque señalan que en la Rumanía actual, las mujeres se retocan sobre todo senos y labios. Nuestras entrevistadas son sumamente críticas con el canon estético actual y la tendencia a exhibirse, así como con la primacía de los dos modelos propulsados por los medios rumanos (Rovenţa-Frumuşani 2002: 94): la mujer objeto, y la mujer ideal de belleza anónimo (como las que aparecen en shows televisivos). Hay que recordar que gran parte de nuestras entrevistadas son migrantes de motivación económica, por tanto su fin primordial en España es trabajar y ahorrar. El esfuerzo material que supone el mantenimiento de una determinada imagen impuesta por la sociedad de acogida no parece ser prioritario para estas mujeres, salvo con fines de movilidad social, como es el caso de Florica: "con la vestimenta también se metía [mi jefe]. Si iba seria decía que tengo el estilo rumano, que somos musulmanes-ortodoxos. La costumbre nuestra es ir a la oficina vestidos clásico, pantalón de pinza y camisa; empecé a ir con pantalones ajustados, camisas largas con cinturón y escote generoso. Mi compañero decía: 'Si yo miro, figúrate como mira el que entra por primera vez' y yo contestaba 'para eso me han puesto aquí'”. A este respecto, se podría decir, que si bien nuestras entrevistadas no narraban situaciones en las que incorporasen el uso de la imagen en las estrategias de búsqueda de empleo (porque tampoco la indagación científica sobre este aspecto se incluyó en el guión), sí repararon en las pautas estéticas como estrategias de preservación del empleo, tanto en el testimonio de Florica (que adopta el escote pronunciado a instancia del jefe), como en el de Ana, quien narraba que "la señora para quien trabajaba se fijaba en cómo me vestía [...] Sentía que me miraba cómo me vestía, cómo me comportaba, cómo hablaba, cómo me movía, para no distraer la atención del señor, y al notar esto, supe mantenerme en mi línea, así que no llegamos a conflictos".

En tercer lugar, las mujeres son conscientes de que custodian los valores tradicionales y estéticos a través de la apariencia y conducta, aún en situación migratoria, aunque se observan cambios. Algunas de las entrevistadas (las de más edad y que además han pasado su infancia en el medio 
rural: Ana, Ioana) sienten una responsabilidad como portadoras de la cultura tradicional y se enorgullecen de ello, aunque se muestran bastante flexibles ante los cambios requeridos por la cultura del país receptor o por los condicionantes específicos (grupo social en el que se integran que puede no coincidir con el de origen, tipo de trabajo que suele ser inferior al desempeñado en origen, lugar de residencia, etc., pues algunas decisiones en lo corporal tienen que ver con la profesión, religión, edad o entorno). Según hemos visto, no renuncian a los cuidados del pelo y cosmética, aún en contexto económico precario (aunque sí a la manicura por imperativos de trabajo o falta de tiempo). Siguen otorgando importancia al oro, aunque reconocen la practicidad de la bisutería. Aprecian la "relajación" en la vestimenta española, aunque mantienen la etiqueta en determinados contextos sociales. En lo que se refiere a los principios básicos, se aferran a la tradición de no exhibirse demasiado, no perder de vista los valores (familia, hogar, educación de los hijos), respetar la indumentaria propia de los encuentros formales: trabajo, teatro, médico, y en este sentido, activan mecanismos de resistencia, aunque se muestran flexibles en algunos aspectos y capaces de combinar lo que ellas llaman "estilo rumano" y "español".

Por último, parece que nuestras informantes de mayor edad no han llegado a interiorizar los preceptos estéticos y el canon de construcción corporal reinante en la sociedad de acogida (en su lugar de trabajo, de residencia, o en su grupo social de interrelación) mientras que las más jóvenes parecen someterse al control de la sociedad de llegada. Entre las mujeres entrevistadas no hemos detectado casos de control social ejercido por la sociedad de partida, si bien se advierte en la comunidad rumana residente en España el sometimiento a normas estéticas de control remoto en pos del reconocimiento por parte del grupo, en el caso de quienes opten por un modelo de enclave rumano en España, anti-aculturación, generalmente de corte profesional o corporativo. La corporeidad diaspórica parece sublevarse ante la pretensión de control social por parte de la sociedad receptora, una vez conquistado el distanciamiento de la rigidez del canon de partida, no sin cierta nostalgia y no sin aspectos definitorios de la sociedad rumana actual, de los cuales, el subconsciente de estas mujeres es portador, sobre todo las de más edad. Y esto por varias razones que podrían ser: su educación y el hecho de sentirse transmisoras de valores recibidos en su infancia preservados por la dictadura y perpetuados en la época post-dictatorial, cuya latencia se reaviva a través del contacto a distancia con la cultura de origen gracias a la explosión tecnológica y la globalización. 


\section{BIBLIOGRAFÍA CITADA}

Antal, I. 2007. Violenţa domestică. Suport de curs. Disponible en: xa.yimg.com/ kq/groups/ 21041747/1003343816/name/suport

Antohi, S. 2009. "Perpetuum mobile: note despre emigraţia din România postcomunistă", en R. G. Anghel y I. Horváth (eds.), Sociologia migraţiei. Teorii şi studii de caz româneşti: 289-300. Iaşi: Polirom.

Bban, A. y H. P. David. 1996. "The Impact of Body Politics on Women's Bodies", en M. Feischmidt, E. Magyari-Vincze y V. Zentai (coords.), Women and men in East European transition: Summer School, Cluj, July 23-28, 1996: 156-170.

Brbulescu, C. 2005. Imaginarul corpului uman. Între cultura țărănească şi cultura savantă (secolele XIX-XX). Bucarest: Paideia.

Bodeanu, D. F. 2002. "Politica demografică a regimului comunist reflectată în revista Femeia (1966-1989)", en G. Cosma y V. Ţărău (coords.), Condiția femeii în secolul XX, vol. 2: 135-190. Cluj-Napoca: Presa Universitară Clujeană.

Ceimigra. 2008. Informe anual sobre Migraciones e Integración. Valencia: CEIMIGRA.

Chasseguet-Smirgel, J. 2003. Corpul ca oglindă a lumii. Bucarest: Ideea Europeană.

Cormoş, G. 2006. Femei în infernul concentraționar din România (1945-1989). ClujNapoca: Editura Casa Cărţii de Ştunţă.

Cosma, G. 2002. "Presa femenină dup model sovietic. Studiu de caz 'Femeia' (1948-1958)", en G. Cosma y V. Ţărău (coords.), Condiţia femeii în România secolului XX. Studii de caz. Vol. 2: 135-172. Cluj-Napoca: Presa Universitară Clujeană.

Diminescu, D. 2009. "Exerciţiul dificil al liberei circulaţii: o introducere în istoria migraţiei recente a românilor", en R. G. Anghel y I. Horváth (eds.), Sociologia migrației. Teorii Şi studii de caz româneşti: 45-62. Iaşi: Polirom

Enăchescu, C. 2005. Fenomenologia trupului. Locul şi semnificația Trupului carnal în psihologia persoanei. Bucarest: Paideia.

Esteban, M. L. 2004. Antropología del cuerpo. Género, itinerarios corporales, identidad y cambio. Barcelona: Edicions Bellaterra.

Featherstone, M. 1991. "The body in consumer culture", en M. Featherstone, M. Hepworth y B. S Turner (eds.), The Body, Social Process and Cultural Theory: 170-196. Londres: Sage.

Foucault, M. 2003. Vigilar y castigar. Nacimiento de la prisión. Reimpresión. Buenos Aires: Siglo XXI.

Hurubean, A. 2011. "Mass-media Şi democraţia în România postcomunistă", en Sfera Politicii 155. <http://www.sferapoliticii.ro/sfera/155/art05-Hurubean.php> (consulta, agosto 2011)

Kligman, G. 2000. Politica duplicitţii. Bucarest: Humanitas.

Le Breton, D. 1990. Antropología del cuerpo y modernidad. Buenos Aires: Editorial Nueva Visión.

Le Breton, D. 2002. Sociología del cuerpo. Buenos Aires: Ediciones Nueva Visión.

Lipovetsky, G. 1999. La tercera mujer. Barcelona: Editorial Anagrama.

Marcu, S. 2003. "El proceso de transición política en Rumania: herencias y realidades poscomunistas", en Estudios Internacionales 7: 1-41, <http://www.reei.org/reei7/ S.Marcu.pdf> (consulta, agosto 2011) 
Marcu, S. 2008. "Sobrevivir a la transición. La emigración internacional de rumanos desde un enfoque territorial. Cuadernos de Geografia 84: 135-152.

Marcu, S. 2010. "20 años después. Nuevos valores en la sociedad civil de la Rumanía postcomunista". Política y Sociedad 47 (3): 219-238.

Martí Pérez, J. 2008. La cultura del cuerpo. Barcelona: Editorial UOC.

Massino, J. 2004. "Anonimatul femeii în estetica României Ceauşiste", en A. Ciupală (ed.), Despre femei şi istoria lor în România. Bucarest: Editura Universitcii. <http:// ebooks.unibuc.ro/istorie/ciupala/anonimatulfemeii.htm> (consulta, agosto 2011)

Menéndez Menéndez, M. I. 2006. El zapato de Cenicienta. El cuento de hadas del discurso mediático. Oviedo: Trabe.

Merleau-Ponty, M. 1999. Fenomenologia percepției. Oradea: Aion.

Moise, E. 2003. "Interpretarea Bibliei, sursă a discriminărilor de gen în practica religioasă creștină din România. O analiză de gen a trei dintre practicile religioase creştine din România". Journal for the Studies of Religion E Ideologies 6: 149-164 <http://jsri.ro/ojs/ index.php/jsri/article/viewFile/144/144> (consulta, agosto 2011)

Morar-Vulcu, C. 2002. "Între 'noi' şi 'ei': identitatea politică a femeii în discursul comunist", en G. Cosma y V. Ţârău (coords.) Condicţia femeii în România secolului XX. Studii de caz. Vol. 1: 199-211. Cluj-Napoca: Presa Universitară Clujeană.

Nash, M. 2005. "La doble alteridad en la comunidad imaginada de las mujeres inmigrantes", en M. Nash, R. Tello y N. Benach (eds.) Inmigración, género y espacios urbanos. Los retos de la diversidad: 17-31. Barcelona: Bellaterra.

Olteanu, C. L. 2004. "Cultul Elenei Ceauşescu în anii '80", en Alin Ciupală (ed.) Despre femei şi istoria lor în România. Bucarest: Editura Universităţii. <http:// ebooks.unibuc.ro/istorie/ciupală/cultuleneceausescu.htm> (consulta, agosto 2011)

Pasti, V. 2003. Ultima inegalitate. Iaşi: Polirom.

Pérez Gauli, J. C. 2000. El cuerpo en venta. Madrid: Cátedra.

Roca i Girona, J. 1996. De la pureza a la maternidad. La construcción del género femenino en la postguerra española. Madrid: Ministerio de Educación y Cultura.

Rovenţa-Frumuşani, D. 2002. "Identitatea feminină şi discursul mediatic in România postcomunistă", en Å. Brădeanu, et al. (eds.), Femei, cuvinte şi imagini. Perspective feministe: 48-123. Iaşi: Polirom.

Soley-Beltran, P. 2005. "Modelos de feminidad", en Congreso Nacional XXV Años de Estudios de Género. Mujeres Sabias, entre la teoría y la práctica: 430-434. Castellón: Fundación Isonomía.

Stanek, M. 2009. "Los inmigrantes rumanos y búlgaros en España: perfiles socio-demográficos y pautas migratorias", en D.-S. Reher y M. Requena (eds.), Las múltiples cara de la inmigración en España: 217-250, Madrid: Alianza.

Ţârău, V. 2002. "De la diversitate la integrare. 'Problema femeii' şi instaurarea comunismului în Europa Centrală şi de Est: Cazul României», en G. Cosma y V. Ţârău (coords.), Condiţia femeii în România secolului XX. Studii de caz. Vol. 1: 135-159. Cluj-Napoca: Presa Universitară Clujeană.

Viruela Martínez, R. 2008a. "Europeos del Este en el mercado de trabajo español. Un enfoque geográfico". Revista CIDOB d'Afers Internacionals 84, Migraciones y redes transnacionales: Comunidades inmigradas de Europa Central y del Este en España: 81-103.

Viruela Martínez, R. 2008b. “Población rumana y búlgara en España: evolución, distribución geográfica y flujos migratorios". Cuadernos de Geografía 84: 169-194. 
Viruela Martínez, R. 2010. "Movilidad geográfica de los rumanos (Estructura territorial de las migraciones interiores en España)". Empiria 19: 157-181.

Woodcock, S. 2004. "Gen, etnie şi spaţiu. Discursuri despre violenţa sexuală asupra femeii în Bucureşti”, en A. Ciupală (ed.), Despre femei şi istoria lor în România. Bucarest: Editura Universitţii. <http://ebooks.unibuc.ro/istorie/ciupala/ genetnie.htm> (consulta, agosto 2011)

Fecha de recepción: 11 de octubre de 2011

Fecha de aceptación: 26 de marzo de 2012 